\title{
The "pandemic» period of the education system crisis: peculiarities of the modern telecommunication systems and messenger's implementation as the alternative didactic platforms for the linguistic disciplines teaching
}

\author{
Anna Reznikova, ${ }^{1, *}$, Taisija Kudinova ${ }^{2}$, Regina Patuykova ${ }^{3,}$ Natalya Olomskaya $^{3}$, and \\ Oksana Dyshekova ${ }^{4,1}$ \\ ${ }^{1}$ The Don State Technical University, 344003, Gagarin sq., 1, Rostov-on-Don, Russia \\ ${ }^{2}$ The All-Russian State University of Justice (RLA of the Ministry of Justice of Russia), 344112 , \\ Rostov Branch (Institute), Studencheskaya str, 6, Rostov-on-Don, Russia \\ ${ }^{3}$ The Kuban State University, 350040, Stavropolskaya str., 149, Krasnodar, Russia \\ ${ }^{4}$ The Russian Customs Academy, 344002, Rostov Branch, Budennovsky str., 20, Rostov-on-Don, \\ Russia
}

\begin{abstract}
The article aims to highlight the problems of a Higher education during the period of self-isolation caused by the $2019-\mathrm{nCoV}$ (SARS-CoV-2) pandemic in Russia and describe an analysis of a personal pedagogical experience of the authors. It is noted that despite the technical difficulties appeared at the beginning of a transition to a new learning model by the means of online educational platforms, pedagogical activity during the pandemic was an example of a competent organization of the educational process. The article focuses on the positive aspects of distance learning in terms of improving the skills of independent work using telecommunication technologies and messengers, but nevertheless points out some serious drawbacks of online learning. It is emphasized that the quality of classes conducted in distance way was not reduced due to the creative approach of teachers using classical and media-educational technologies as innovative. The results of a distance educational activity during the pandemic are considered as a preparatory stage of a teaching society to overcome the crisis in education by combination of traditional and distance methods of teaching.
\end{abstract}

\section{Introduction}

The year of 2020 was historically marked by a great biological conflict - a pandemic, the spread of a previously unknown disease that has been registered as 2019-nCoV (SARSCoV-2) or simply Covid-19. The fear of the unknown turned out to be worse than the virus itself: the global community was plunged into an anxious termination of the completion of

\footnotetext{
* Corresponding author: annreznikova@yandex.ru
} 
the global threat hanging over the civilization. It was believed that the origins of Covid-19 have come from China. Human activity, normal to our routine life, came to a standstill. Despite the fact that the authorities of the Chinese province of Hubei, considered to be a hotbed of infection, made utmost efforts to prevent the spread of infection, the situation could not be contained. The virus, spreading its tentacles, took over the entire world in just a few weeks. The high level of virulence and contagiousness of SARS-CoV-2 stopped the activity of society in the usual traditional way: news reports on the number of infected, sick and dead from coronavirus infection were listened as war reports. Humanity "hid" in a deep underground $-\mathrm{a}$ "regime of self-isolation" was announced. All possible and previously impossible measures were taken to contain and counteract the spread of the disease. Production and industries were stopped, trade was prohibited, schools, colleges and universities, cultural institutions, social and sports facilities were closed. Many organizations had to implement the format of distance work that ensured the safety of citizens' health. Educational institutions of all levels had to turn to the distance learning as well.

The closure of schools and universities due to the coronavirus disrupted the full educational process for about 1 billion students and schoolchildren in 160 countries [UN Secretary-General Antonio Guterres, retrieved from: https://www.interfax.ru/world/720181], referring to data for mid-July, accounting for $91.3 \%$ of all students worldwide. In most countries, educational institutions have been closed completely or partially, and many students were transferred to distance learning. The closure of schools and the emergency transition to distance learning were associated with obvious problems, mainly due to the insufficient technical equipment (lack of infrastructure for mass distance education), lack of technical training of teachers to work in the new conditions.

Efforts to provide lessons online, on radio and television did not reach all students. And even before the pandemic, more than 250 million school-age children were excluded from school, and in developing countries only a quarter of children finished school with the necessary basic skills.

Antonio Guterres considers the present day educational situation in the framework of a pandemic to be a "generational catastrophe" resulting in a huge human potential loss.

These and other problems have seriously challenged the education system in a critical situation. First of all, here is a table summarizing the dates of transition to distance learning in various countries affected by the pandemic:

Table 1. Measures taken in various countries of the world within the educational sphere in connection with the spread of 2019-nCoV (SARS-CoV-2) and the announcement of a pandemic (eg., 10 countries with the largest quantity of infected people)

\begin{tabular}{|c|c|c|c|}
\hline № & Country & $\begin{array}{l}\text { Date of the first measures for complete } \\
\text { or partial closure of educational } \\
\text { organizations start }\end{array}$ & $\begin{array}{l}\text { Date of a total lock down of } \\
\text { educational organizations of } \\
\text { all levels }\end{array}$ \\
\hline 1 & China & 08.02 .2020 & $\begin{array}{l}08.02 .2020 \text { (all educational } \\
\text { institutions are closed) }\end{array}$ \\
\hline 2 & Italy & 24.02 .2020 & $\begin{array}{l}04.03 .2020 \quad \text { (all educational } \\
\text { institutions are closed) }\end{array}$ \\
\hline 3 & The United States of America & 28.02 .2020 & $\begin{array}{l}28.02 .2020 \\
\begin{array}{l}\text { (educational } \\
\text { institutions are closed in } 48 \\
\text { states) }\end{array}\end{array}$ \\
\hline 4 & $\begin{array}{l}\text { The United Kingdom of Great } \\
\text { Britain and Northern Ireland }\end{array}$ & 28.02 .2020 & $\begin{array}{l}16.03 .2020 \text { (all educational } \\
\text { institutions are closed) }\end{array}$ \\
\hline 5 & Germany & 03.03 .2020 & $\begin{array}{l}03.03 .2020 \text { (the most part of } \\
\text { educational institutions are } \\
\text { closed) }\end{array}$ \\
\hline 6 & India & 04.03 .2020 & $\begin{array}{l}04.03 .2020 \text { (all educational } \\
\text { institutions are closed) }\end{array}$ \\
\hline
\end{tabular}




\begin{tabular}{|l|l|l|l|}
\hline 7 & Spain & 11.03 .2020 & $\begin{array}{l}12.03 .2020 \text { (all educational } \\
\text { institutions are closed) }\end{array}$ \\
\hline 8 & Brazil & 12.03 .2020 & $\begin{array}{l}12.03 .2020 \text { (educational } \\
\text { organizations are closed } \\
\text { partially, taking into account the } \\
\text { epidemiological situation in the } \\
\text { region) }\end{array}$ \\
\hline 9 & The Russian Federation & 16.03 .2020 & $\begin{array}{l}23.03 .2020 \text { (all educational } \\
\text { institutions are closed) }\end{array}$ \\
\hline 10 & Turkey & 16.03 .2020 & $\begin{array}{l}23.03 .2020 \text { (all educational } \\
\text { organizations are closed, online } \\
\text { learning for primary and } \\
\text { secondary school is organized } \\
\text { via national television and the } \\
\text { Internet). }\end{array}$ \\
\hline
\end{tabular}

It should be noted that the closure of educational institutions did not happen at once, the governments of some countries were slow to make a decision, but however, the transition to distance learning was inevitable for the most of them.

\section{Problem statement}

The problem of implementation of distance learning technologies into traditional curriculum is not new: the pros and cons of implementing distance learning methods in the traditional educational process have been discussed by researchers and teachers for quite a long time. Experts in the field of crisis research in the education sphere even in the beginning of the $70 \mathrm{~s}$ of the $\mathrm{XX}$ century declared a possible global crisis in the teaching methodology and didactics and negative consequences for the education system lagging behind other social spheres in the framework of technical progress. Research of distance forms and methods of teaching in online mode is reflected in the works of such domestic and foreign scientists as N.B. Evtukh, T. Kulikova, M.Yu. Karpenko, D.M. Dzhusubalieva, S.P. Kudryavtseva, B.I. Shunevich, I. McPhee, D. Marks, I. Duffy, A. Okaz, M. Paechter, B. Mayer, etc. The main aspect of discussion always consists in debates of a distance learning pros and cons. In fact there is no definite answer whether it is good or evil as it is obvious that an implementation of any innovation should be started with a change of traditional methods that would take much effort. Moreover, some researchers consider elearning to be quite new and unexplored issue, despite it has numerous advantages. [1-2] Another scientists believe that it is challenging to be adapted to the online learning environment. [3]

Fully online and hybrid or blended courses that integrate Information and Communication Technologies (ICT) and complement traditional classroom practice are on the rise nowadays in the field of language teaching. The aim of these courses is to offer flexible learning formats for learners of all ages in the way of tailor-made instruction which can adapt to their needs and expectations. They seem to be suited to diverse educational and social needs and provide, as well as demand, active engagement. [4]

Faculty commitment to instructional design and delivery is pivotal for creating effective virtual environments. The literature indicates that faculty needs to recognize that e-teaching requires design expertise and delivery skills (Salyers et al., 2014). Courses must be designed so that students could benefit from the interactive potential of online learning (Thorpe, 2002), so instructors require extensive training on how to utilize new technologies and adapt teaching methods to distance learning environment (Valentine, 2002). [5] 


\section{Research questions}

The authors have made an effort to summarize existing definitions of distance learning phenomenon and present their own idea of the process. It is necessary to consider all the peculiarities of the distance learning process both positive and negative and give a definition to the concept taking them in account.

- to represent an individual pedagogical experience of a distance learning to linguistic disciplines implementation

It should be noted that the transition to distance learning was a kind of a shock therapy, thanks to which an educational system was not paralyzed. It is obvious that the biological menace clearly demonstrated the beginning of a new period of the global educational crisis; we consider the biological threat to a human life to be a start of a new point of an educational rise. An unexpected shakeup brought the teaching society all over the world to the understanding of an urgent necessity of didactics changes and methodological improvements of the curriculum. Though we were not ready for such a challenge as a complete transition from the traditional educational model to the immediate and total implementation of telecommunication systems and messengers as the only possible educational instruments, we managed it without any decline of educational level.

A wise decision of the Russian President Vladimir Putin making a decree declaring the first week of the pandemic self-isolation as non-working hours made it possible for the specialists in the education sphere to react to the situation and organize the training within a new format considering the current circumstances. Due to the use of telecommunication systems (Zoom, TrueConf, GoogleMeet, etc.) didactic platforms and messenger programs (WhatsApp, Skype, Facebook Messenger, etc.), as well as due to the enthusiasm of a teaching staff, the training process was well-prepared and restored during the first week off. Understanding the severity of a dangerous virus spreading problem has led to a positive attitude of students to online classes. Let's note a curious fact: the percentage of attendance of lectures and seminars during a distance learning format was much higher than during contact classes.

- to describe pros and cons of a distance learning implementation into a traditional curriculum

A careful analysis of pros and cons of a distance learning implementation into a traditional curriculum is given according to a personal experience of the authors as teachers of linguistic disciplines.

- to outline a complex of measures in order to improve the traditional methodology by implementing distance forms of learning as innovative methods of teaching linguistic disciplines.

The authors analyzed personal pedagogical experience during a pandemic distance learning and found it possible to conclude the following:

- there is an urgent necessity for our country to work out a domestic telecommunication system targeted to its further implementation into educational process as a means of distance learning in particular;

- it is necessary to implement distance learning technologies into everyday curriculum. It would give much profit to both, the students and educational institutions;

- it is important to pay attention to a traditional contact teaching methodology and didactics and transform it according to the social demand using innovative and interactive technologies as a part of a contact teaching.

\section{Research methods.}

1.1 Analysis. 
1.2Data collection.

1.3 Observation.

\section{Findings}

The year of 2020 would never be forgotten by a global society: it is a year brought changes to any possible life sphere from health care to educational field. We faced the greatest challenge ever and it gave an understanding of a further direction in development in the sphere of education. The ongoing life processes have confirmed the predictions given about a collapse of a traditional educational model. So, we consider the pandemic to be a trigger of implementation of new technical skills, innovative teaching methods, creativity. Under the new conditions of life, the world of digital technologies was taken as an urgent necessity without any possibility of escape. The time of the pandemic switched the educational system into a remote mode everywhere. A distance learning methodology had to be implemented immediately in order not to stop a curriculum. It should be noted that Russian educational system managed it almost perfect; all the educational institutions were transferred to a distance learning format and the curriculum was rearranged at once.

Generally speaking, a concept of distance learning is not new; this phenomenon has been discussed for several decades already and defined thousands of times. Some definitions seem to deal only with behavior (Schunk, 2000), some only with knowledge (Mayer, 1987) and some deal with both knowledge and observable behavior (Slavin, 1994). The United States Distance Learning Association defined distance learning (Roblyer, Edwards, 2000) as the acquisition of knowledge and skills through mediated information and instruction, encompassing all technologies and other forms of learning at a distance. Newby, Stepich, Lehman and Russell (2000) define distance learning as an organized instructional program in which teacher and learners are physically separated.

T. Kulikova defines a concept of a distance learning as "a set of educational technologies with mediated or partially mediated interaction between a student and a teacher that is carried out regardless of their location and distribution in time, based on pedagogically organized information technologies, primarily by means of telecommunication systems or television". [6]

We believe that distance learning (e-learning) can be defined as a complex of educational technologies that fully meet the needs and requirements of the curriculum within a particular discipline or course by technical means ensuring continuous contactless interaction between a teacher and a student in case of geographical, time or pandemic constraints for contact study.

It is rather difficult for us to imagine that in some low-income countries any form of education was not available in the context of the pandemic, since $64 \%$ of the inhabitants of these countries have no access to the Internet. The Russian reality against the background of these indicators is quite different.

It should be noted that the majority of teachers of the Russian Universities have chosen popular telecommunication platforms while teaching students in a distance mode. For example, Zoom, Google Meet, Skype, Discord platforms were used by the language teachers of the Don State Technical University and the Russian Customs Academy; TrueConf as a didactic platform was chosen by the Rostov Institute (branch) of All-Russian State University of Justice (RLA of the Ministry of Justice of Russia) teaching stuff; the Kuban State University teachers implemented the Microsoft Teams system and Moodle platform. In addition, we noted that the electronic information and educational system of a higher education institution that was created in advance played a significant role in a correct organization of a distance learning process. The formation of the existing electronic 
educational database including lectures, practical workshops, test blocks, PowerPoint presentations during the pandemic was significantly boosted: for instance, the general amount of educational courses worked out by the teachers of the Don State Technical University was increased from couple of hundreds to about a thousand without any loss of an educational value. The significant electronic resource that couldn't be overestimated is the distance electronic learning portal Skif, created by the teaching stuff of the Don State Technical University on the basis of the Moodle platform and supplemented during distance learning period (https://test.skif.donstu.ru/).

Similar educational resources in some other universities solved the problem of educational and methodological support of disciplines successfully as well as issues related to the implementation of intermediate control of students' knowledge.

However, it was the pandemic that expanded the content boundaries of this area of educational activity. Up to this point, the use of information and educational environment materials was partial. Students' access to resources was carried out mainly for checkout the command of a discipline in the test mode.

In addition, we should note that a self-isolation conditions contributed to a deeper formation of a professional competence of students based on the organization of their independent work. This point was facilitated by the additional free time available for students as there was no need to spend time getting to the Universities and back home. In addition, it became possible not only to refine the basic knowledge but also to deepen and expand it by internet surfing for new information on their own to get ready for classes.

An experience of a distance course management shows that it is very important to motivate students to work actively non-stop. It sounds unexpectedly but it turned out students' awareness that constant and hard work during e-learning could bring double profit:

- primarily, a distance learning gave an opportunity to spend more time for study as well as for entertainment due to a better time management;

- e-learning provided a wider range of possibilities of an individual creative work based on individual approach to preparation to distance classes;

- e-learning involved the most part of students into a self-study model according to which a student takes a responsibility of a preparation quality to himself personally. This aspect, to our opinion, became one of the most important motivating points for a students' progress during a pandemic distance learning.

Despite the growing number of non-traditional adult students in online higher education, little is known about the dynamic processes of adult distance learning, through which adult students struggle to develop their learning ability, to balance their life and study, and to become self-regulated learners - ultimately competent selves and lifelong learners. [7]

Gibbs and Simpson (2004) advocate for regular, comprehensive, and detailed feedback as the main interactive component of teaching. They conclude that only immediate and specific feedback provided by instructors enables students to gain control over their learning and monitor their own performance. Distance students, due to their backgrounds, may also feel more pressure to collaborate and be part of the team (Valentine, 2002). [8]

Another significant aspect of a pandemic distance learning success is a lack of communication; deficiency of face-to-face interaction stimulated high students' attendance rate to interactive classes as they could meet each other there and communicate within a curriculum and besides it. Experience has shown that attendance tutorials are also important for distance learning. It is essential, however, to explain to students that tutorials do not take the form of a lecture but a consultation. Students who attended regular tutorials usually had better results. 
But it should be mentioned that we speak exactly about the pandemic period of distance learning as it was a forced self-isolation time, though if we discuss e-learning as a phenomenon of our ordinary everyday life there wouldn't be any lack of communication and this aspect wouldn't play any important role in a student's progress. However, an interesting fact is that a lack of communication can be taken both as a positive mark from a teacher's point of view and disadvantage according to students' idea.

It is clear that a distance learning process involves at least two participants, a teacher and a student. Students just as teachers are divided into two opposite camps voting in favor and against distance learning.

The most common advantages of distance learning given by students are the following:

- an opportunity to study at work, [8]

- the possibility to study in time that the student determines himself,

- the possibility to plan work and study mode individually,

- flexible hours and the permission not to attend University daily,

- low cost of study in case of distance learning,

- the possibility to obtain a curriculum by a disabled people.

There are several principles of distance learning:

1. The principle of accessibility can be explained as a right of any person having a desire and under certain conditions (e.g. age of 18, completed secondary education etc.) to get a higher education no matter what his social status and geographical location are. Distance learning is available to everyone in any place of study due to distance educational technologies implementation.

2. The second principle of distance learning is flexibility according to which the learning process can be divided into modules (blocks) and every student should manage time given to the particular module learning himself focusing on final goals.

3. The third principle of distance education is motivation of students to use their practical experience and basic knowledge to learn something new via self-study.

4. The fourth principle is the principle of adequacy of learning technologies for distance education models.

5. The fifth principle of distance education is learning mobility. It consists in creating information networks, databases and knowledge banks for students allowing them to achieve the scores in training programs individually in accordance with their needs and intellectual level. [9].

6. The sixth principle of distance learning is the importance of individuality. It means that the individual features of the student should be taken into account.

7. Humanism of education is the seventh principle of distance learning: directing the learning process to the needs of a particular student and creating the necessary conditions for all students to acquire a high level of knowledge. [10,11].

But, of course, besides a number of positive aspects we can point out a lot of negative issues to be improved or even get rid of and we offer you to study analytics made by RAEX concerning the students' opinion towards pros and cons of a distance learning format. The focus group involved six thousand students of higher educational institutions from all over the Russian Federation. 


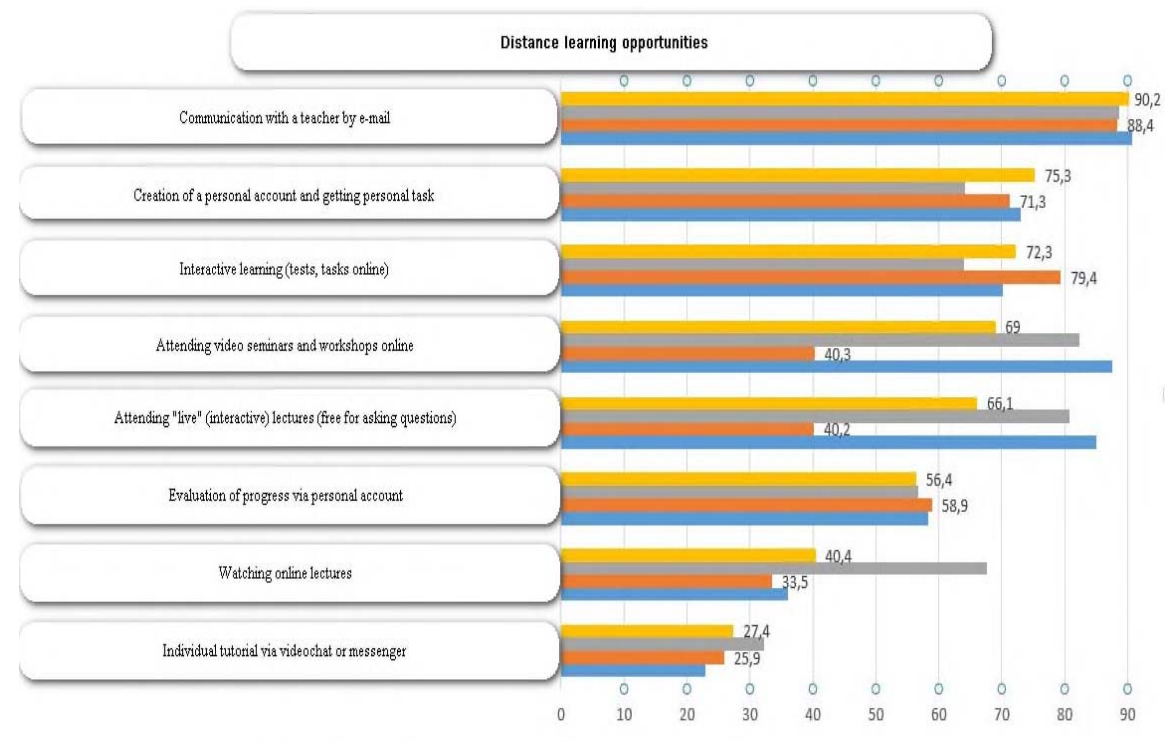

Fig.1. Distance learning opportunities

(Here, yellow - Higher educational institutions of the Russian Federation (in average); orange - regional Higher educational institutions; grey - Moscow Higher educational institutions (location); blue - RAEX top-20 Higher educational institutions)

Generally, the results of the survey are the following: it was predictable that technical support and didactics of the capital higher educational institutions would be much better than in regional universities (it is presented in Fig.2). Although it's interesting that over $70 \%$ of a focus group members pointed out a lack of communication with group mates and a teacher as a main drawback of an educational process in a distance mode;

- $36,9 \%$ of respondents reported a challenge of self-control and self-organization;

- $58,1 \%$ of students drew attention to the problem of technical support and weak programming of educational apps (it should be noted, that the percentage of students dissatisfied with technical support was higher in the regions $-71,2 \%$ vs. $47 \%$ in Moscow). [12]

It should be pointed out that distance learning requires students and teachers to have a completely different approach than regular daytime lessons. As demonstrated by practical experience, this is a very demanding form of education and therefor some other negative aspects arise:

- students and many teachers have little or no experience with this form of education. It is important to keep in mind age and technical illiteracy of some teachers; it is obviously impossible or extremely difficult for them to learn the latest computer technologies in the shortest possible time that's why teachers feel they can use the same pedagogical and didactic practices as in full-time teaching. As opposite to full-time teaching, it is necessary to provide an extensive preparation for the distance and combined forms. Students must already have all study materials, assignment of correspondence tasks, technically prepared control systems, means of communication, and so on. However, this requires a lot of work both technically and methodically and didactically. [13]

- teaching requires students to be highly motivated and able to deal with time efficiently, complex and demanding preparation of teaching and study materials.

Also it's necessary to add that e-learning delivers even more fundamental disadvantages besides those already discussed:

- more considerable difficulty in understanding some terms, 
- retaining motivation for the study.

- safety of personal data

- stable and constant operation of technical devices, software and multimedia educational platforms.

First, in practical classes, instead of traditional explanation made by a teacher a new format of a self-study was implemented. It required a better self-organization and a broad outlook in order to get ready for the classes and try to understand the material individually. It turned to be an utmost difficulty while teaching foreign languages and any linguistic disciplines. Indeed the modern telecommunication systems offer an improved functionality; the advantages of such systems are obvious: simple interface, unlimited number of conference participants, the ability of high-quality interactive work (watching video lessons, listening to audio lessons, demonstration the teacher desktop with continuous audio-video contact with the audience, etc.).

Lack of speech activity also influences to motivation, it is extremely difficult to stay motivated with a feeling of "restricted competition". It should be admitted that lack of speech activity does not contribute to the competitive spirit that usually reigns in contact classes. Some researches consider the traditional lesson to be a fundamental didactic unit, a form of the educational process through which a certain amount of knowledge is assimilated by the students in a predetermined amount of time, through intentional, systematic activities. [14] So, speaking activities are better realized during the face-t-face interaction. And at last let's define one of the most important drawbacks depicted by both, students and teachers, - a technical problem that can be divided into two parts.

The first technical problem is a system error of resources. In almost all communication systems with a large number of users, there were interlocks or even total shutdowns. However, we are not talking about a particular messenger or a didactic platform. Teachers and students of both higher and secondary educational schools using different resources (Uchi.ru, RES, InternetUrok.ru, Coursera, etc.) experienced great inconvenience. It was the huge overload of platforms due to the mass users' connection that caused technical failures, which were accompanied by system interlocks and shutdowns. As a result, students had to work with video and audio modes disconnected. It was hard time for the teachers used to traditional contact training. The teachers did not understand the student's reaction to the represented information, since they couldn't see or even hear their students, while the use of written communication slowed down the pace of classes. In order to keep in touch, a teacher had to interrupt the class with a frequent call such as "Can you hear me?" or "Do you understand me?" We suppose these calls distracted students from fixing certain lecture aspects. We believe that technical failures occurred due to insufficient preparation of the servers for such a loading.

The lack or low competitiveness of domestic software and high-tech developments in the field of telecommunication technologies, especially providing distance learning is another crucial technical problem. For this reason, most colleagues were forced to use the Zoom platform as a telecommunication didactic platform but it is known to have a low level of personal data security and periodically pops up in the news in the context of another scandal due to the leak of personal data of users to the network.

But nevertheless the Zoom platform was admitted to be one of the most appropriate telecommunication systems for a distance teaching of linguistic disciplines due to its functionality. Using Zoom gives an opportunity for a broad interaction with the audience; it provides audio and visual contact with students and simultaneous demonstration of a teacher's desktop presenting any kind of online task such as video presentation, listening comprehension with subtitles if necessary, PowerPoint presentation, online knowledge test and many other different variants of tasks. Moreover, the presentation and demonstration of any kind of task doesn't restrict the communication of a student and a teacher, they can see 
each other face to face and keep a visual connection. It helps to focus on the communicative aspect through the prism of critical thinking development.

It should be noted that teaching society turned to distance educational technologies long before the pandemic but it was a bit too cautious: there were timid attempts to work via Skype and Whatsapp messenger. And we must admit that Whatsapp brilliantly coped with the task assigned to him to coordinate the actions of the teacher and students at the very beginning of self-isolation time. Besides coordination the use of Whatsapp messenger chats has a lot of advantages:

- it gives an opportunity to unite the entire language group within the same goals. It creates a sense of belonging to something unifying and peculiar only to this particular community. Hence the feeling of significance arises in each member of the group, makes people to support each other that produces a sense of security allowing reveal their personality openly. This effect is very important in case of language learning as it reduces the fear of making a mistake during speaking or writing foreign language;

- another positive aspect is writing skills automatism. This is a utilitarian skill but extremely important because it is impossible to carry out full-fledged communication in any foreign language without it;

- Whatsapp messenger chat can also be used as a storage of different important information from links to some useful resources to textbooks, dictionaries and instructions necessary for study. It is an utmost convenience that helps to be always ready to improve your command [15-16].

\section{Conclusion}

A thorough analysis of our personal pedagogical experience during the period of a pandemic distance learning allows us to draw the following conclusions:

- there is an urgent necessity for our country to work out a domestic telecommunication system targeted to its further implementation into educational process as a means of distance learning in particular. It should meet the demands of the teachers of any profile and give an opportunity to humanitarians to carry out teaching process in full without a decline in a level of achievements;

- it is necessary to implement distance learning technologies into everyday curriculum. It would give much profit to both, the students and educational institutions. It also should be taken into account that requirements of students are constantly changing and they expect flexible learning opportunities reach in technologies. [17] In fact, some educational games can be used to widen knowledge and practical skill development. It also helps to enrich students' projects, portfolios and html pages. [18]

- it is important to pay attention to a traditional contact teaching methodology and didactics and transform it according to the social demand using innovative and interactive technologies as a part of a contact teaching.

Today, the level of civilization has expanded the functions of the teacher. The main goal of a teacher's activity is to integrate the knowledge of the University program with the available information in the media. The use of media materials and various modern technical tools makes the process optimal, that is, information is not only easily received, but also critically analyzed, compared and evaluated by students. Distance learning technology is a way of teaching students certain skills in an integrating space of program and non-program realities.

As we can see, the pragmatic aspects are evident, that is, during the pandemic, the skills of independent work are improved in the distance learning mode, which contributes to the development of intelligence in a professional direction. However, it should be recognized that with the visible and undeniable advantages of using distance learning methods, there 
are also a huge number of shortcomings, that is, we should not assume that the experience of a complete transition to distance learning was completely successful: the teaching community was able to identify and present several deep and significant shortcomings of this educational model.

Assessing the results of activities in Russian education during the pandemic, we believe that in overcoming the crisis in education in general, one of the links in the chain of events should be a pedagogical model for the harmonious organization of contact and distance classes, where it is possible to combine new technologies with media technologies.

\section{References}

1. C. A. Lemnaru, E-Learning for foreign languages. European Proceedings of Social and Behavioral Sciences, 23, 1889-1894 (2016) https : // doi:10.15405/epsbs.2017.05.02.232

2. C. L. Bloju, The Utilization Of E-Learning Instruments In Consolidation Activities Of The Grammar Elements. European Proceedings of Social and Behavioral Sciences, 23, 400-405 (2016) https://doi.org/10.15405/epsbs.2017.05.02.49

3. E. Lewandowska, Children's Well-Being and Distance Learning During Pandemics Covid-19. European Proceedings of Health, 7-13 (2020) https://doi.org/10.15405/19006.2020.xx.xxx2.

4. M. Arrosagaray, M. González-Peiteado, M. Pino-Juste, B. Rodríguez-López, A comparative study of Spanish adult students' attitudes to ICT in classroom blended and distance language learning modes. Computers \& Education, 134, 31-40 (2019) https://doi.org/10.1016/j.compedu.2019.01.016

5. T. Markova, I. Glazkova, E. Zaborova, Quality Issues of Online Distance Learning. Procedia - Social and Behavioral Sciences, 237, 685-691 (2017) https://doi.org/10.1016/j.sbspro.2017.02.043

6. T. Kulikova, N. Poddubnaya, A. Ardeev, G. Shagrova, Innovative approaches to the organization of students' independent learning in accordance with the digital economy requirements, 205-212 (Stavropol - Dombay, Russia, 2019) http://ceur-ws.org/Vol2494/paper_19.pdf. (Last accessed 15.08.2020)

7. K. Lee, H. Choi, H. Yo. Cho, Becoming a competent self: A developmental process of adult distance learning. The Internet and Higher Education, 41, 25-33, (2019) https://doi.org/10.1016/j.iheduc.2018.12.001

8. O. Pozdnyakova, A. Pozdnyakov, Adult Students' Problems in the Distance Learning. Procedia Engineering, 178, 243-248 (2017) https://doi.org/10.1016/j.proeng.2017.01.105

9. S. Costareie, Assuring quality based on the assessment of learning outcomes. 5th International Technology, Education and Development Conference (INTED), 32353236 (Valencia, Spain, 2011)

10. P. Moskal, Ch. Dziuban, J. Hartman, Blended learning: A dangerous idea? Internet and Higher Education, 18, 15-23 (2013) DOI:10.1016/j.iheduc.2012.12.001

11. O. Kuznetsova, Distance learning: pros and cons. International journal of applied and fundamental research, 8(2), 362-364 (2015) Retrived from: URL: https://appliedresearch.ru/ru/article/view?id=7101 (Last accessed 25.08.2020).

12. Distance learning 2020 (2020) Retrieved from: https://raexa.ru/researches/distance_education/2020 (Last accessed 25.08.2020) 
13. D. Jucan, Interactive Teaching-Learning Methods within the Academic Course EpSBS, 67, 936-944 (2018) https://doi.org/10.15405/epsbs.2019.08.03.113.

14. A. Reznikova, A. Vnukovskaya, To the issue of a possibility of «Whatsapp» messenger use as a didactic platform and a means of psychological adaptation of the foreign students within the teaching Russian language as a foreign. The Bulletine of the Ufa Law Institute of the Ministry of Internal Affairs of Russia, 4(86), 183-187 (2019)

15. T. Usmanova, The didactic opportunities of distance learning within foreign writing teaching. The world of pedagogy, 5(22), 11-17 (2018)

16. A. Lami, The potential Role of Technology in Foreign Language Teaching Process. EpSBS, 67, 683-680 (2019) https : // doi.org/10.15405/epsbs.2019.08.03.80

17. W. Veen, B. Vrakking, Homo Zappiens. Game and playing in digital era. Sigma Publishing House (2011)

18. S. Hutasuhut, B. Irwansyah, A. Rahmadsyah, R. Aditia, Impact of business models canvas learning on improving learning achievement and entrepreneurial intention. Cakrawala Pendidikan, 39(1), 168-182 (2020) 